\section{Iron-containing phases in metallurgical and coke dusts as well as in bog iron ore}

\author{
Tadeusz Szumiata, \\ Marzena Rachwal, \\ Tadeusz Magiera, \\ Katarzyna Brzózka, \\ Małgorzata Gzik-Szumiata, \\ Michał Gawroński, \\ Bogumil Górka, \\ Joanna Kyziol-Komosińska
}

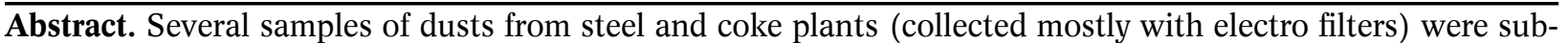
jected to the investigation of content of mineral phases in their particles. Additionally, sample of bog iron ore and metallurgical slurry was studied. Next, the magnetic susceptibility of all the samples was determined, and investigations of iron-containing phases were performed using transmission Mössbauer spectrometry. The values of mass-specific magnetic susceptibility $\chi$ varied in a wide range: from 59 to above $7000 \times 10^{-8} \mathrm{~m}^{3} \cdot \mathrm{kg}^{-1}$. The low values are determined for bog iron ore, metallurgical slurry, and coke dusts. The extremely high $\chi$ was obtained for metallurgical dusts. The Mössbauer spectra and X-ray diffraction patterns point to the presence of the following phases containing iron: hematite and oxidized magnetite (in coke and metallurgical dusts as well as metallurgical slurry), traces of magnetite fine grains fraction (in metallurgical dusts), amorphous glassy silicates with paramagnetic $\mathrm{Fe}^{3+}$ and $\mathrm{Fe}^{2+}$ ions, traces of pyrrhotite (in coke dusts), $\alpha-\mathrm{Fe}$ and nonstoichiometric wüstite (in metallurgical slurry), as well as ferrihydrite nanoparticles (in bog iron ore). For individual samples of metallurgical dusts, the relative contributions of $\mathrm{Fe}^{2+/ 3+}$ ions in octahedral $\mathrm{B}$ sites and $\mathrm{Fe}^{2+}$ ions in tetrahedral A sites in magnetite spinel structure differs considerably.
\end{abstract}

Keywords: metallurgical dusts $\bullet$ coke dusts $\bullet$ bog ore $\bullet$ phase analysis $\bullet$ Mössbauer spectrometry $\bullet$ magnetic susceptibility

T. Szumiata ${ }^{\bowtie}$, K. Brzózka, M. Gzik-Szumiata,

M. Gawroński, B. Górka

Department of Physics,

University of Technology and Humanities in Radom,

54 Krasickiego Str., 26-600 Radom, Poland,

E-mail: t.szumiata@uthrad.pl

M. Rachwał, J. Kyzioł-Komosińska Institute of Environmental Engineering of the Polish Academy of Sciences, 34 Skłodowska-Curie Str., 41-819 Zabrze, Poland

T. Magiera

Department of Land Protection,

Opole University,

22 Oleska Str., 45-052 Opole, Poland

Received: 25 June 2016

Accepted: 3 October 2016

\section{Introduction}

Currently, many investigations on environmental pollution have been carried out. A special emphasis is placed not only on the extent and amount of pollutants but also on their geochemical, mineralogical, and phase composition. In spite of the emission rate reduction, industrial dusts produced by different kinds of industry still have hazardous impact on the environment $[1,2]$. Integrated magnetic, geochemical, and mineralogical methods have been applied in research that aimed at characterization of these different dusts, which contain technogenic magnetic particles (TMPs) arisen during high-temperature technological processes [3, 4]. TMPs are mostly iron oxides with ferrimagnetic or antiferromagnetic properties; therefore, their presence in dusts, soils, and sediments can be easily detected by simple magnetic measurements [5]. Conditions and mechanisms of dust formation (e.g., temperature, oxygen availability, kind of fuels, and additives used) specific for different technological processes determine the magnetic and mineralogical properties of TMP [6] as well as the amount and the type of bonding of another elements such as heavy metals, which can be 
incorporated into TMP's crystal lattice or adsorbed on their surfaces [7].

In case of the proper interpretation of magnetic signal measured in bulk samples of soil or sediment material coming from environmental samples (soil, sediments), it is very important to distinguish between its natural and anthropogenic origin. The most commonly used magnetic parameter is magnetic susceptibility $(\chi)$ because it is very easy measurable even in field conditions. Magnetic susceptibility is a concentration-dependent parameter and is related to the content of all magnetic particles of both natural and anthropogenic origins in measured sample [8].

Natural concentration of ferrimagnetic and antiferromagnetic iron forms are typical for iron bog ores commonly occurred in hypergenic zone, revealing the predominance of meteoric water circulation with concomitant oxidation and chemical weathering. Bog iron ores in Poland are Holocene terrestrial iron accumulation occurring in wet, shallow depression several centimetres below the land surface within the zone of groundwater oscillation. Processes of bog iron accumulation are controlled mainly by $\mathrm{pH}$ and Eh conditions that determine the structure of various iron ores. The ores consist predominately of the iron oxyhydroxides: ferrihydrite, goethite, and sometimes lepidocrocite. These are accompanied by variable amounts of siliciclastic material (such as quartz and feldspars). The most important mineral phase in Holocene iron ores is goethite, which often coexists with metastable ferrihydrite [9].

The main goal of the present work was the thorough identification of iron-containing mineral phases in the different kinds of industrial dusts (metallurgical and coke dusts) and slurries as well as bog ore samples. The important task was the determination of the contributions of $\mathrm{Fe}^{3+}$ and $\mathrm{Fe}^{2+}$ ions as well as verification of the presence of glassy phases. Special attention was paid to the influence of fine sizes of dust particle on the resulting Mössbauer spectra, including superparamagnetic effects, structural defects, and nonstoichiometry of iron oxides.

\section{Experimental}

The samples of dusts from steel and coke plants (located in southern Poland) as well as metallurgical slurry were the object of the phase analysis. The dusts were the mixture of particles of wide range sizes, including submicrometre-sized fraction. Additionally, the Holocene bog iron ore from Mazovia (central Poland) was investigated as an example of natural nanomaterial containing iron. The samples of industrial dusts were collected with different methods. The detailed specification of the samples is given in Table 1 . First, specimens were placed in $10-\mathrm{cm}^{3}$ vessels and weighted. Next, the magnetic susceptibility of all samples was determined using Bartington MS2 magnetic susceptibility meter equipped in dual-frequency MS2B sensor. Subsequently, mass-specific magnetic susceptibility $(\chi)$ was calculated from the following equations: $\chi=$ $\chi_{v} / \rho\left[\mathrm{m}^{3} \cdot \mathrm{kg}^{-1}\right]$, where $\rho$ was the bulk density of a sample $\left[\mathrm{kg} \cdot \mathrm{m}^{-3}\right]$ and $\chi_{v}$ the volume-specific magnetic susceptibility as dimensionless SI quantity [10]. Then, investigations of iron-containing phases were performed using transmission ${ }^{57} \mathrm{Fe}$ Mössbauer spectrometry at room temperature. The spectrometer equipped with ${ }^{57} \mathrm{Co}(\mathrm{Rh})$ source and arranged in vertical configuration was operating in constant acceleration mode. The Mössbauer spectra were fitted by means of PolMoss package based on MS Excel and Solver extension using parallel gradient and evolutionary optimization algorithms dedicated for multicore processors. All fitted subspectra had the form of Voigt profile as a result of the Lorentzian baseline convolution with Gaussian distributions of hyperfine parameters. The same software and fitting method was successfully used in the case of dusts from highways and fly ashes from power plants and heat plants $[11,12]$. X-ray powder diffraction (XRD) analyses were carried out by means of Bruker D8 ADVANCE apparatus equipped with a position-sensitive linear detector VANTEC-1. Quantitative analysis was conducted using the Rietveld method with TOPAS software.

Table 1. Specification of samples and their mass-specific magnetic susceptibility $\chi$

\section{Sample label}

MET1-P1

MET2-P4

MET3-P5

COK1-P2

COK2-P3

COK3-P7

SLUR-P9

\section{Description}

Metallurgical dust from sintering plant no. 1,

collected in electrostatic precipitator

Metallurgical dust from sintering plant no. 2, collected in electrostatic precipitator

Metallurgical dust from belt conveyor of blast furnace charge preparation unit

Magnetic susceptibility $\chi\left[\times 10^{-8} \mathrm{~m}^{3} \cdot \mathrm{kg}^{-1}\right]$

7513.6

6480.6

6172.4

Coke dust from sorting plant collected in electrostatic

$$
\text { precipitator }
$$

Coke dust from coke grinder collected by manual sweeping

Coke dust from coke battery collected by manual sweeping

Metallurgical slurry from wet dedusting of blast furnace, steelworks, and sintering plant

Bog iron ore 


\section{Results and discussion}

The values of mass-specific magnetic susceptibility $(\chi)$ varied in a wide range: from 59 to above 7000 $\times 10^{-8} \mathrm{~m}^{3} \cdot \mathrm{kg}^{-1}$ (Table 1$)$. The lowest $\chi$ values were determined for bog iron ore. Metallurgical slurry and
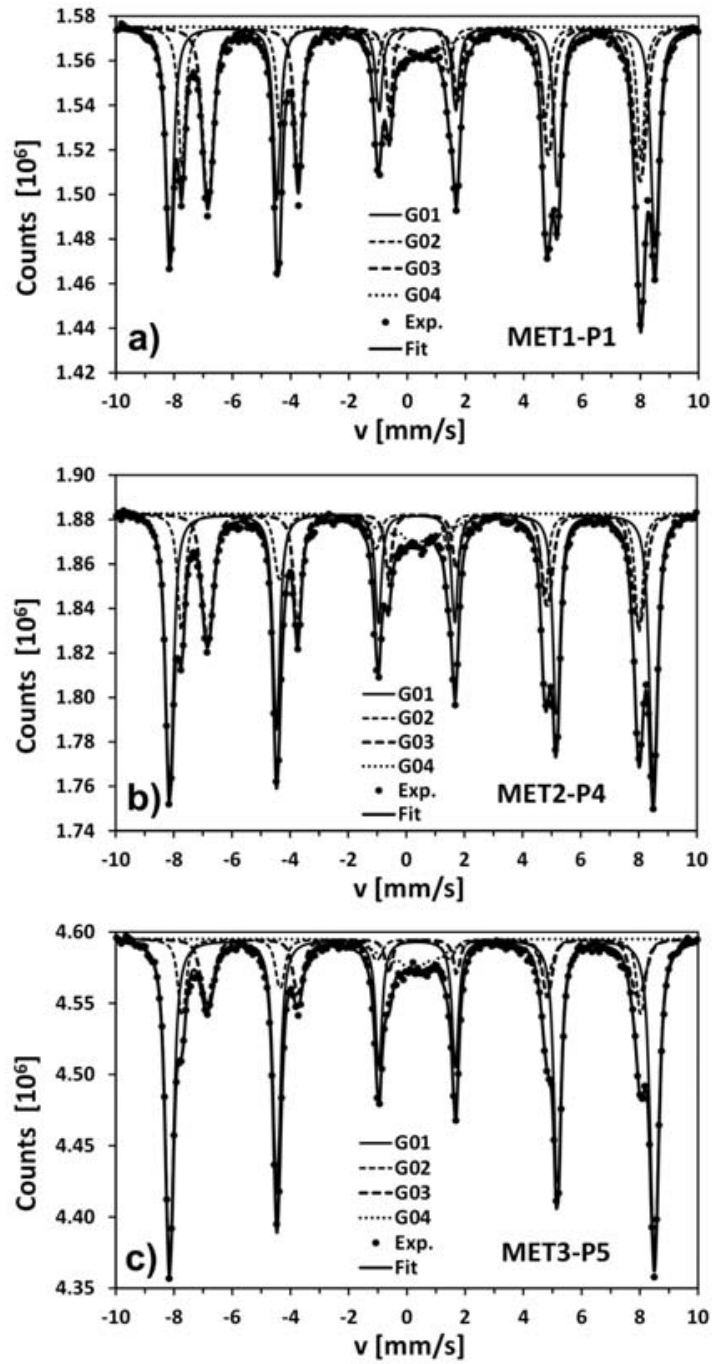

Fig. 1. Room-temperature transmission Mössbauer spectra for samples of metallurgical dusts.

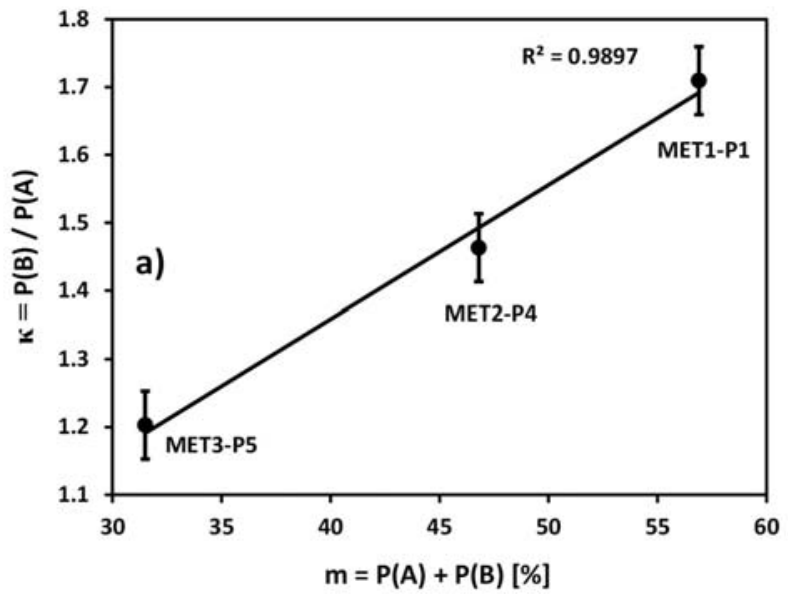

coke dust samples exhibit higher $\chi$ values of $254 \times$ $10^{-8}$ and $291459 \times 10^{8} \mathrm{~m}^{3} \cdot \mathrm{kg}^{-1}$, respectively. The extremely high $\chi$ values were obviously obtained for metallurgical dusts $\left(6172-7514 \times 10^{-8} \mathrm{~m}^{3} \cdot \mathrm{kg}^{-1}\right)$. High $\chi$ values of dusts resulted from the occurrence of ferromagnetic or ferrimagnetic iron particles that arose during technological high-temperature processes when different forms of iron minerals were transformed into ferrimagnetic iron oxides. As magnetic susceptibility is concentration-dependent parameter, the higher concentration of ferromagnetic or ferrimagnetic forms of iron in metallurgical dusts caused the extreme increase in $\chi$ value.

The Mössbauer spectra of metallurgical dusts are presented in Fig. 1 $(\mathrm{a}-\mathrm{c})$, whereas the hyperfine parameters of the individual subspectra are listed in the first part of Table 2. The highest hyperfine field component (G01) corresponds to the hematite [13]. The contribution of $\mathrm{Fe}$ atoms belonging to hematite (relatively to all iron atoms in all phases) increases from about $37 \%$ in the first sample to almost $62 \%$ in the third sample in which the hematite is a dominating phase. This change is correlated with the drop in magnetic susceptibility (Table 1) because antiferromagnetic hematite exhibits lower $\chi$ values than ferrimagnetic forms. The next two components (G02 and G03) have been attributed to the magnetite (the presence of both magnetite and hematite has also been confirmed in XRD patterns, Fig. 2a). The hyperfine field values of corresponding two components differ by no more than $0.1-0.2 \mathrm{~T}$ and isomer shift (IS) values by no more than $0.01-0.02 \mathrm{~mm} \cdot \mathrm{s}^{-1}$ in comparison with the reference data for stoichiometric, bulk magnetite (Table 2) [14, 15]. However, a significant discrepancy is observed in the ratio of intensities of components G03 and G02, which corresponds to the contributions of $\mathrm{Fe}^{2+/ 3+}$ ions in octahedral $\mathrm{B}$ sites and iron $\mathrm{Fe}^{3+}$ ions in tetrahedral A sites in magnetite inverse spinel structure $\left[\mathrm{Fe}^{3+}\right]^{\mathrm{A}}\left[\mathrm{Fe}^{3+} \mathrm{Fe}^{2+}\right]^{\mathrm{B}} \mathrm{O}_{4}$, respectively. The value of $\kappa=P(\mathrm{~B}) / P(\mathrm{~A})$ ratio in the stoichiometric magnetite is equal to 2 , whereas in the investigated samples, this ratio ranges from 1.7 to 1.2 . The drop in $\kappa$ ratio value is linearly correlated with the decrease in total percentages $m=P(\mathrm{~A})+P(\mathrm{~B})$ of $\mathrm{Fe}$ atoms belong-

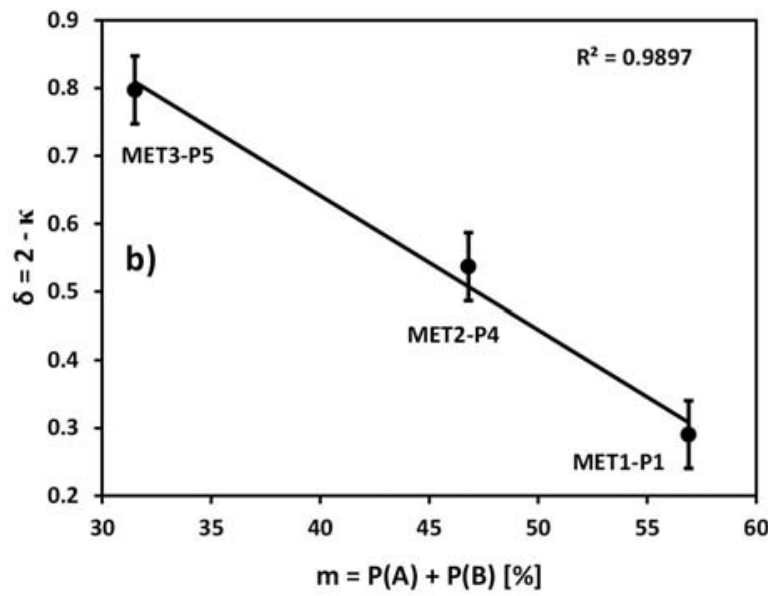

Fig. 2. (a) The ratio $\kappa$ of iron ions contributions in B sites (octahedral) and A sites (tetrahedral) in magnetite spinel structure as well as (b) atomic concentration $\delta$ of vacancies in octahedral sites vs. total percentages of iron atoms $m$ belonging to magnetite in metallurgical dusts determined by means of room-temperature Mössbauer spectrometry. 
Table 2. Best-fit hyperfine parameters of different components of the transmission Mössbauer spectra for the samples of metallurgical dusts, coke dusts, metallurgical slag, and bog iron ore. Symbols and their meanings: IS $_{0}$, mean value of the isomer shift distribution; $\Delta(\mathrm{IS})$, variance of isomer shift distribution; $\mathrm{QS}_{0}$, mean value of quadrupole splitting; $B_{0}$, mean value of hyperfine field distribution; $\Delta(B)$, variance of hyperfine field distribution; $P$, percentage contribution. Isomer shift values have been given relatively to $\alpha$-Fe. The uncertainties of parameters are smaller than first cut digit

\begin{tabular}{|c|c|c|c|c|c|c|c|c|}
\hline $\begin{array}{c}\text { Sample } \\
\text { label }\end{array}$ & Component & $\begin{array}{c}\mathrm{IS}_{0} \\
{[\mathrm{~mm} / \mathrm{s}]}\end{array}$ & $\begin{array}{c}\Delta(\mathrm{IS}) \\
{[\mathrm{mm} / \mathrm{s}]}\end{array}$ & $\begin{array}{c}\mathrm{QS}_{0} \\
{[\mathrm{~mm} / \mathrm{s}]}\end{array}$ & $\begin{array}{c}\Delta(\mathrm{QS}) \\
{[\mathrm{mm} / \mathrm{s}]}\end{array}$ & $\begin{array}{l}B_{0} \\
{[\mathrm{~T}]}\end{array}$ & $\begin{array}{c}\Delta(B) \\
{[\mathrm{T}]}\end{array}$ & $\begin{array}{c}P \\
{[\%]}\end{array}$ \\
\hline \multirow{4}{*}{ MET1-P1 } & G01 & 0.372 & 0.005 & -0.168 & -0.004 & 51.84 & 0.41 & 37 \\
\hline & G02 & 0.271 & 0.019 & -0.043 & -0.018 & 49.05 & 0.25 & 21 \\
\hline & G03 & 0.675 & 0.021 & 0.024 & -0.004 & 46.17 & 0.88 & 36 \\
\hline & G04 & 0.453 & -0.006 & 0.000 & 0.000 & 7.27 & 4.06 & 6 \\
\hline \multirow{4}{*}{ MET2-P4 } & G01 & 0.374 & 0.004 & -0.174 & 0.000 & 51.81 & 0.47 & 46 \\
\hline & G02 & 0.278 & -0.040 & -0.067 & 0.079 & 49.00 & 0.38 & 19 \\
\hline & G03 & 0.680 & 0.025 & 0.030 & -0.016 & 46.18 & 0.97 & 28 \\
\hline & G04 & 0.451 & 0.002 & 0.000 & 0.000 & 6.95 & 4.33 & 7 \\
\hline \multirow{4}{*}{ MET3-P5 } & G01 & 0.370 & 0.001 & -0.175 & 0.007 & 51.85 & 0.48 & 62 \\
\hline & G02 & 0.291 & 0.065 & -0.052 & -0.127 & 49.06 & 0.48 & 14 \\
\hline & G03 & 0.653 & 0.006 & 0.003 & 0.028 & 46.06 & 1.13 & 17 \\
\hline & G04 & 0.302 & -0.018 & 0.000 & 0.000 & 6.22 & 3.77 & 7 \\
\hline \multirow{6}{*}{ COK1-P2 } & G01 & 0.360 & 0.000 & -0.163 & 0.000 & 51.84 & 0.10 & 13 \\
\hline & G02 & 0.305 & 0.000 & -0.012 & 0.000 & 48.99 & 0.44 & 17 \\
\hline & G03 & 0.632 & 0.000 & 0.040 & 0.000 & 45.26 & 0.87 & 7 \\
\hline & G04 & 0.834 & 0.000 & 0.000 & 0.000 & 28.59 & 2.31 & 13 \\
\hline & G05 & 0.903 & 0.492 & 1.391 & 0.180 & 0.00 & 0.00 & 35 \\
\hline & G06 & 0.237 & 0.076 & 0.848 & 0.116 & 0.00 & 0.00 & 15 \\
\hline \multirow{6}{*}{ COK2-P3 } & G01 & 0.316 & 0.000 & -0.339 & 0.000 & 51.07 & 0.10 & 3 \\
\hline & G02 & 0.308 & -0.009 & -0.035 & 0.000 & 48.94 & 0.38 & 7 \\
\hline & G03 & 0.623 & -0.250 & 0.020 & 0.000 & 45.47 & 0.77 & 7 \\
\hline & G04 & 0.486 & 0.000 & 0.000 & 0.000 & 29.40 & 3.00 & 17 \\
\hline & G05 & 1.045 & 0.476 & 1.226 & 0.000 & 0.00 & 0.00 & 15 \\
\hline & G06 & 0.353 & 0.050 & 0.664 & 0.000 & 0.00 & 0.00 & 51 \\
\hline \multirow{6}{*}{ COK3-P7 } & G01 & 0.387 & 0.000 & -0.184 & -0.002 & 51.42 & 0.10 & 17 \\
\hline & G02 & 0.275 & 0.047 & 0.016 & 0.012 & 49.05 & 0.25 & 12 \\
\hline & G03 & 0.881 & 0.059 & -0.026 & 0.249 & 45.50 & 0.51 & 6 \\
\hline & G04 & 0.978 & 0.000 & 0.000 & 0.000 & 28.00 & 3.00 & 10 \\
\hline & G05 & 0.543 & 0.215 & 1.394 & 0.000 & 0.00 & 0.00 & 9 \\
\hline & G06 & 0.328 & 0.092 & 0.674 & 0.000 & 0.00 & 0.00 & 46 \\
\hline \multirow{6}{*}{ SLUR-P9 } & G01 & 0.393 & 0.000 & -0.211 & 0.000 & 51.87 & 0.00 & 10 \\
\hline & G02 & 0.224 & 0.000 & 0.075 & 0.000 & 48.78 & 0.34 & 5 \\
\hline & G03 & 0.627 & 0.000 & 0.059 & 0.000 & 45.98 & 1.70 & 9 \\
\hline & G04 & -0.009 & 0.005 & 0.001 & 0.000 & 33.06 & 0.07 & 25 \\
\hline & G05 & 1.023 & 0.136 & 0.710 & 0.000 & 0.00 & 0.00 & 21 \\
\hline & G06 & 0.630 & 0.359 & 0.943 & 0.000 & 0.00 & 0.00 & 30 \\
\hline \multirow{3}{*}{ OREB-P8 } & G01 & 0.521 & 0.000 & 0.000 & 0.000 & 21.57 & 7.00 & 9 \\
\hline & G02 & 0.366 & 0.000 & 0.594 & -0.149 & 0.00 & 0.00 & 56 \\
\hline & G03 & 0.360 & -0.003 & 1.070 & -0.234 & 0.00 & 0.00 & 35 \\
\hline
\end{tabular}

ing to magnetite in relation to other iron-containing phases (Fig. 3a). The observed nonstoichiometry of magnetite could be explained in terms of the model proposed by Gorski and Scherer [16]. In the case of the fine particles of magnetite, one can expect surface defects - predominantly the vacancies in octahedral positions. The general formula of such defected magnetite could be expressed as $\left[\mathrm{Fe}^{3+}\right]$ ${ }_{\text {Tet }}\left[\mathrm{Fe}^{2+}{ }_{1-3 \delta} \mathrm{Fe}^{3+}{ }_{1+2 \delta} \square_{\delta}\right]^{\text {]ct }} \mathrm{O}_{4}$, where symbol $\square$ denotes vacancies and letter $\delta$ their atomic concentration. Thus $\delta$ quantity can be expressed by $\kappa$ ratio by a simple relation: $\delta=2-\kappa$. In our case, the drop in magnetite content in metallurgical dusts is accompanied by the increase in the vacancies concentration in this phase (Fig. 3b). In general, the higher value of $\delta$ is determined (smaller $\kappa$ ) and the higher oxidation degree of magnetite is observed. In particular, when concentration of vacancies takes a value 
$\delta=1 / 3$, the stoichiometry corresponds to the totally oxidized magnetite, that is, maghemite $\left(\gamma-\mathrm{Fe}_{2} \mathrm{O}_{3}\right)$ $[17,18]$. However, in the case of two investigated metallurgical dusts (MET2-P4 and MET3-P5), the value of $\delta$ is higher than $1 / 3$. In order to avoid the unphysical result of the oxidation degree of iron higher than $3+$, it should be concluded that iron vacancies are presumably accompanied by the vacancies in oxygen sites. It is possible at the strongly defected surface of the magnetite fine particles. Interesting feature of the obtained results is the fact that despite significant discrepancies in A-site and B-site occupations, the hyperfine field values of the obtained spectra are closer to magnetite than to maghemite $[17,18]$. The serious difficulty in analysing the magnetite Mössbauer spectra is the fact that even above the Verwey transition (charge ordering transition around $120 \mathrm{~K}$ ), the spectrum consists of three - not two - components because of mixed valency $\left(\mathrm{Fe}^{2+} / \mathrm{Fe}^{3+}\right)$ at octahedral B sites [19]. Unfortunately, in the case of fine particles and the complex mixture of various phases, it is very difficult to resolve two components corresponding to
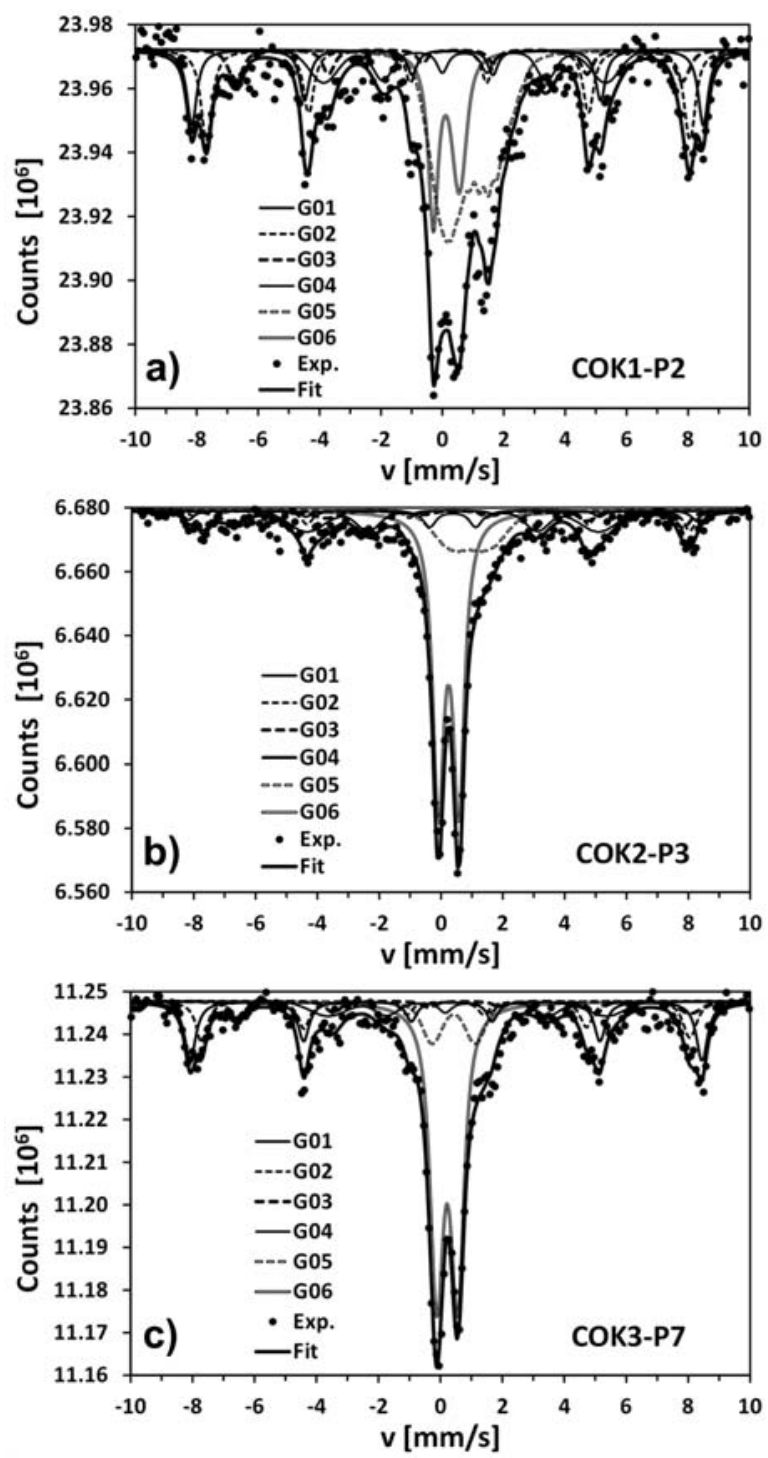

Fig. 3. Room-temperature transmission Mössbauer spectra for samples of coke dusts.
$\mathrm{B}$ site. They are visible as one Zeeman sextet with broadened hyperfine distribution with the variance larger about three times than that for A-site component, which is seen in Table 2. It is worth adding that two first samples of metallurgical dusts contain more stoichiometric magnetite than the last one (and they were the most magnetic) - probably because they came from the unit of ore sintering (Table 1). The last low-field component G04 present in the spectra of metallurgical dusts corresponds probably to the finest fraction of magnetite for which thermal magnetic relaxation effects weaken the effective hyperfine magnetic field but not significantly affect the IS and quadrupole splitting (QS) values (Table 2). The contribution of this fraction is relatively low (6-7\%) in comparison with the dominating large-grain fractions. In the metallurgical dusts, no glassy phase was found - neither in the Mössbauer spectra nor in the XRD patterns (Fig. 2a).

In the Mössbauer spectra obtained for the samples of the coke dusts (Fig. 4), the presence of hematite has been stated; however, its contribution is several times smaller than that in the case of the metallurgical dusts and the values of hyperfine fields are slightly reduced (component G01, Table 2). Hematite is also visible in XRD patterns (Fig. 2b). The most hematite-deficient sample is COK2-P3 in which only $3 \%$ of all iron atoms belongs to this phase. This sample reveals the maximum value of magnetic susceptibility within all coke dusts samples (Table 1). In the investigated coke dusts samples, the contribution of the components corresponding to magnetite-like phase ( $\mathrm{G} 03+\mathrm{G} 02)$ is also relatively low (14-18\%); however, the general question occurs, if really the identified phase is a magnetite at all. The values of hyperfine field of G03 component (corresponding to the iron in octahedral B site) are reduced by about $0.7 \mathrm{~T}$ (Table 2) in comparison with the stoichiometric, bulk magnetite $[14,15]$. However, more pronounced difference is visible in the $\kappa=P(\mathrm{~B}) / P(\mathrm{~A})$ ratio. Instead of the expected $\kappa$ value close to 2 , this ratio takes lower value of 0.5 for COK1-P2 and COK3-P7 samples. It could suggest that in this case, G03 and G02 correspond not to magnetite but possibly to the magnesium ferrite. For this spinel, the corresponding hyperfine field values are very similar to magnetite [20,21]. At room temperature, it reveals inverse-like spinel structure $\left[\mathrm{Mg}_{1-x} \mathrm{Fe}_{x}\right]^{\mathrm{A}}\left[\mathrm{Mg}_{x / 2} \mathrm{Fe}_{1-x / 2}\right]_{2}{ }^{\mathrm{B}} \mathrm{O}_{4}$ with inverse parameter $x$ value close to 0.9 [22], which corresponds to quite low $\kappa$ ratio value - about 1.2 - for bulk, stoichiometric magnesium ferrite. Further drop in $\kappa$-well below 1 - could be explained by the presence of numerous vacancies in B tetrahedral sites at the surface of magnesium ferrite particles. Probably, the lowest value of $\kappa$ for the MET3-P5 sample of metallurgical dust could also be caused by some admixture of magnesium ferrite in magnetite phase. Generally speaking, the magnesium ferrite is a quite common phase in blast furnace charge and products [23]; however, it is hardly distinguishable from magnetite by means of both Mössbauer spectrometry and XRD. The weak point of presented interpretation is the fact that IS values for A and B components 

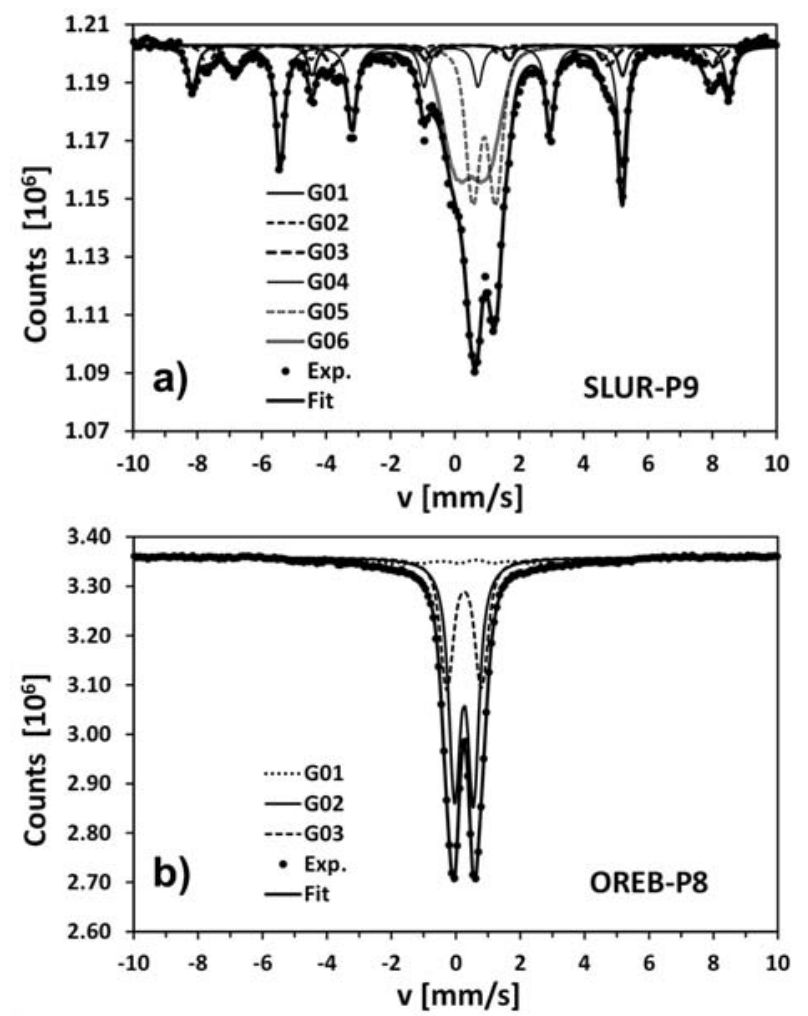

Fig. 4. Room-temperature transmission Mössbauer spectra for samples of (a) metallurgical slag and (b) bog iron ore.

(G03 and G02) in the spectra for all investigated samples are higher than those for bulk magnesium ferrite [20] (closer to bulk magnetite); however, for magnesium ferrite nanoparticles, the increase in IS values was reported in [21]. Additional possible reason for the unexpectedly low experimental values of $\kappa$ parameter in both metallurgical and coke dusts could be a drop in the Debye-Waller factor in B sites of the strongly defected magnetite structure because of the weaker bonding of iron atoms. Another component (G04) of the contribution $10-17 \%$ is characterized by broadened hyperfine field distribution (ca. $29 \pm 3 \mathrm{~T}$, see Table 2) can be associated with pyrrhotite $\left(\mathrm{Fe}_{1-x} \mathrm{~S}\right.$ with $x=0$ to 0.2$)$. Owing to the frequent occurrence of several polytypes of hexagonal or monoclinic crystal symmetry in one specimen, the Mössbauer spectra are usually fitted by three Zeeman sextets [24, 25]. The averaged values of their hyperfine field as well as IS correspond well to $B_{0}$ and IS $_{0}$ values of G04 component (Table 2). Some traces of pyrrhotite phase have been noticed in XRD pattern (Fig. 2b). The presence of pyrrhotite in coke dust was already confirmed by Magiera et al. [1] also by means of Mössbauer spectrometry. Flanders [26] provided the data that pyrite heated to about $1070^{\circ} \mathrm{C}$ in the absence of air dissociates to form pyrrhotite (FeS) and sulphur gas. The dominating components in the Mössbauer spectra of investigated coke dusts are G05 and G06 (together 50-65\%). Both of them are doublets of wide distributions of IS and QS (Table 2); thus it could be associated with paramagnetic iron ions in glassy phase, which is clearly seen in XRD picture (Fig. 2b). In the paper of Anshits [27], the component of similar hyperfine parameters to G05 was attributed to $\mathrm{Fe}^{2+}$ in not well-identified paramagnetic spinel. However, according to Taneja [28] and Ram [29], G05 parameters are also close to those for ankerite $\mathrm{Ca}(\mathrm{Fe}, \mathrm{Mg}, \mathrm{Mn})\left(\mathrm{CO}_{3}\right)_{2}$ carbonate - very common mineral in coal combustions products. In both possible cases, G05 component describes the mineral of strongly defected structure, because of the very broad distribution of IS values (the variance value bigger than $0.4 \mathrm{~mm} / \mathrm{s}$ ). G06 component with considerably lower values of IS and QS comes presumably from paramagnetic $\mathrm{Fe}^{3+}$ ions in amorphous (glassy) aluminosilicates (mullite-porcellanite, $\mathrm{Al}_{6} \mathrm{Si}_{2} \mathrm{O}_{13}$ ), the presence of which in both fly ashes and industrial dusts is widely reported in the literature $[1,12,30]$. The highest contribution of G05 component is stated for the sample COK1-P2 (coke dust collected in electrostatic precipitator), whereas G06 one dominates in the samples COK2-P3 and COK3-P7 (coke dusts collected by manual sweeping). The worse statistic of the Mössbauer spectra for coke dusts is caused by significantly lower iron content than in metallurgical dusts, which is reflected in considerably lower values of magnetic susceptibility (Table 1).

In the case of metallurgical slurry (SLUR-P9), which is a product of wet dedusting of ironworks, in the Mössbauer spectra (Fig. 5a), components corresponding to phases present in both metallurgi-
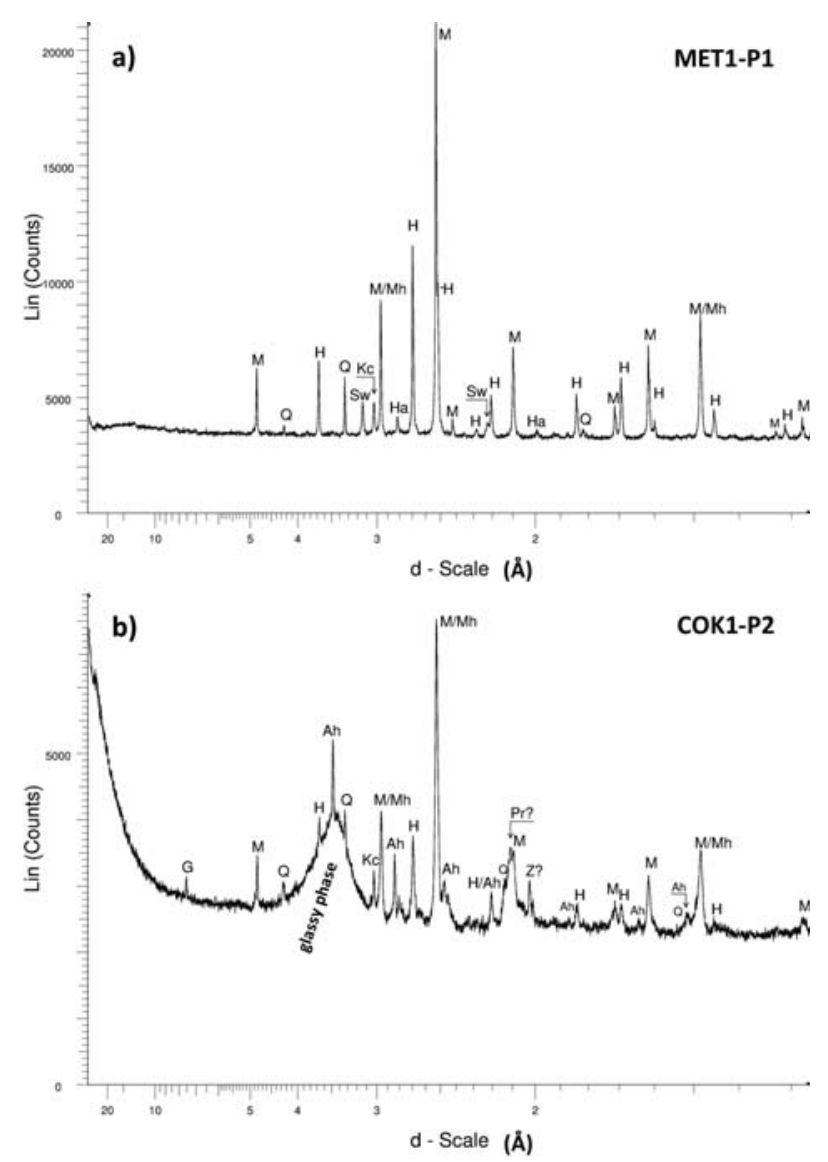

Fig. 5. X-ray diffraction patterns for (a) sample MET1-P1 of metallurgical dust and (b) sample COK1-P2 of coke dust. Abbreviations: Ah, anhydrite; G, gypsum; H, hematite; Ha, halite; Kc, calcite; M, magnetite; Mh, maghemite; Pr, pyrrhotite; Q, quartz; Sw, sylvite; glassy phase, glassy, amorphous silicates. 
cal and coke dusts, that is, hematite and magnetite (9.5\% and $14.8 \%$ of atomic iron contribution for G01 and G02 + G03 components, respectively) can be resolved. On the basis of the data in Table 2, it has been found that the ratio $\kappa=P(\mathrm{~B}) /$ $P(\mathrm{~A})=P(\mathrm{G} 03) / P(\mathrm{G} 02)=1.99$ is almost equal to 2 , which corresponds to the perfectly stoichiometric magnetite. Presumably, it is a simple consequence of the fact that slurry sample contained matter with large, not defected, grains. Next, G04 component (of $25 \%$ contribution) characterized by hyperfine field value of $33 \mathrm{~T}$ and almost zero value of IS as well as zero QS could be attributed to micrometer-sized ferromagnetic $\alpha$-Fe particles (no superparamagnetic effects visible, typical for nanoparticles). The parameters of G05 paramagnetic doublet (of $21 \%$ contribution) correspond well to $\mathrm{Fe}^{2+}$ ions in wüstite (FeO) [31]. The presence of this iron oxide in metallurgical slags and blast furnace sludges was also reported by Jonczy and Stanek [32] and Vereš [33]. The dominating component in the investigated sample is G06 paramagnetic doublet of 30\% contribution. The values of its IS and QS are considerably higher than those for analogous component G06 in coke dusts; however, according to Bajukov [30], it can be still attributed to paramagnetic $\mathrm{Fe}^{3+}$ ions in amorphous aluminosilicate. Such identification with glassy phase is fully justified by considering very high width of IS distribution (variance higher than $0.35 \mathrm{~mm} / \mathrm{s}$ ). Although the investigated sample of metallurgical slurry contains the majority of paramagnetic and antiferromagnetic phases, relatively low value of magnetic susceptibility (Table 1) could be astonishing, because in the specimen, there is almost $40 \%$ of iron atoms in ferromagnetic state (magnetite and iron particles). Presumably, this metallurgical slurry contains significant amount of iron-deficient phases that are not detected by means of Mössbauer spectrometry.

In bog iron ore sample, revealing the lowest magnetic susceptibility, in the Mössbauer spectra (Fig. 5b), one can resolve weak magnetically splitted component G01 (of the contribution less than $10 \%$ ). This component is characterized by broad hyperfine magnetic field distributions of mean value of about $22 \mathrm{~T}$ and the variance of almost $7 \mathrm{~T}$ (Table 2 ). By taking into account the IS value of the order of $0.5 \mathrm{~mm} / \mathrm{s}$ and negligible QS value, G01 component can be attributed to very fine, deformed particles of magnetite. The lower value of hyperfine field value in comparison with the bulk magnetite is a consequence of thermal magnetic relaxation effects in small-sized grains. More than $90 \%$ of spectrum consists of the broadened doublet, which, in fact, is well described by two symmetrically superimposed doublets (G02 and G03). The average values of hyperfine parameters (IS and QS) well correspond to the ferrihydrite $[34,35]$. This mineral of the approximate formula $\mathrm{Fe}_{2} \mathrm{O}_{3} \cdot 0.5 \mathrm{H}_{2} \mathrm{O}$ can be regarded as partially hydrated hematite; however, the precise amount of bonded water is indeterminate. Ferrihydrite is an example of natural nanomaterial, because it only exists in the form of fine grains (usually of strongly defected structure). It is very widespread in the environment, usually comes from aqueous deposits and, similar to limonite (hydrated goethite, $\left.\mathrm{FeO}(\mathrm{OH}) \cdot n \mathrm{H}_{2} \mathrm{O}\right)$, is a basic constituent of bog iron ores. In the past, it was considered as a mixture of several phases. Recently, a single-phase model has been proved, using sophisticated analysis of total X-ray scattering patterns by real-space reconstruction of the pair distribution function from the direct Fourier transformation [36]. The discovered crystalline structure of hexagonal symmetry contains $20 \%$ tetrahedrally and $80 \%$ octahedrally coordinated iron atoms. Additionally, very recent work [34] confirms earlier presumptions that proper analysis of the Mössbauer spectra demands considering the core-shell structure of fine grains of ferrihydrite. In our case, G02 component corresponds to the inner part of the grains, whereas G03 component of similar IS but considerable higher QS is attributed to the surface region of nanocrystallites. The increase in QS value of G03 component is interpreted as a simple consequence of very strong distortion of $\mathrm{FeO}_{6}$ octahedra at the grain surfaces. The presence of structural defects at the surface also causes a significant broadening of QS distribution (Table 2); however, even for "core" component, the variance of QS is high - probably because of the already mentioned fact of not negligible population of tetrahedral coordinations apart from octahedral ones. Considering relative contributions of G02 and G03 subspectra, it can be estimated that almost $40 \%$ of the iron atoms in the ferrihydrite belongs to the surface region of grains. It is not excluded that investigated sample of bog iron ore also contains some amount of limonite, because its mean values of hyperfine parameters IS and QS are close to those for ferrihydrite [37] (though slightly smaller), but because of the natural amorphous atomic structure of limonite, their distributions should be wider than those in ferrihydrite.

\section{Conclusions}

The Mössbauer spectrometry and XRD of metallurgical dusts confirmed that high value of their mass-specific magnetic susceptibility is a consequence of high content of ferrimagnetic magnetite. On the other hand, lower value of magnetic susceptibility of coke dusts was presumably caused by the dominance of glassy and spinel phases with paramagnetic $\mathrm{Fe}^{3+}$ and $\mathrm{Fe}^{2+}$ ions, respectively. In both metallurgical and coke dusts, relatively large grains dominated, revealing neither superparamagnetic behaviour nor other thermal magnetic relaxation effects. Only in metallurgical dusts, some traces of - presumably - fine grains of magnetite was found by means of Mössbauer spectrometry. The sample of metallurgical slurry contained the pure metallic iron particles $(\alpha-\mathrm{Fe})$ characterized by the same hyperfine magnetic field as bulk iron, which pointed to their large sizes. Very pronounced sign of structural defects existence (mostly vacancies) at the surface of porous-structured grains with magnetite-like phases is very small value of $\kappa$ parameter, that is, 
the considerable decrease in the relative contribution of $\mathrm{Fe}^{2+/ 3+}$ ions in octahedral B sites with respect to $\mathrm{Fe}^{2+}$ ions in tetrahedral A sites in magnetite-like inverse spinel structure. Moreover, this trend in the metallurgical dusts was correlated with the increase in hematite content. The significant impact of the size effects was visible in the bog ore sample containing ferrihydrite - natural nanocrystalline mineral. The Mössbauer spectrum analysis showed that in this case, almost $40 \%$ of iron atoms was located at the surface of the grains. This technique also enabled to detect the variety of other phases such as wüstite, pyrrhotite, or magnesium ferrite. In comparison with the road dusts [11], the metallurgical dust and slurry contained significantly less metallic iron. The investigated coke dusts revealed the similar abundance of glassy phase as fly ashes from power plants and heat plants [12]. In general, the content of specific iron-bearing phases in the studied industrial dusts strongly depends on the place of collection of dusty material coming from different stages of blast furnace charge preparation process.

\section{References}

1. Magiera, T., Jabłońska, M., Strzyszcz, Z., \& Rachwał, M. (2011). Morphological and mineralogical forms of technogenic magnetic particles in industrial dusts. Atmos. Environ., 45, 281-290. DOI: 10.1016/j.atmosenv.2011.04.076.

2. Magiera, T., Gołuchowska, B., \& Jabłońska, M. (2013). Technogenic magnetic particles in alkaline dusts from power and cement plants. Water Air Soil Pollution, 224, 1389(17pp.). DOI: 10.1007/s11270-012-1389-9.

3. Rachwał, M., Magiera, T., \& Wawer, M. (2015). Coke industry and steel metallurgy as the source of soil contamination by technogenic magnetic particles, heavy metals and polycyclic aromatic hydrocarbons. Chemosphere, 138, 863-873. DOI: 10.1016/j.chemosphere.2014.11.077.

4. Szuszkiewicz, M., Magiera, T., Kapička, A., Petrovský, E., Grison, H., \& Gołuchowska, B. (2015). Magnetic characteristics of industrial dust from different sources of emission: A case study of Poland. J. Appl. Geophys., 116, 84-92. DOI: 10.1016/j.jappgeo.2015.02.027.

5. Heller, F., Strzyszcz, Z., \& Magiera, T. (1998). Magnetic record of industrial pollution on forest soils of Upper Silesia (Poland). J. Geophys. Res., 103(B8), 17767-17774. DOI: 10.1029/98JB01667.

6. Gupta, S., Dubikova, M., French, D., \& Sahajwalla, V. (2007). Characterization of the origin and distribution of the minerals and phases in metallurgical cokes. Energy Fuels, 21, 303-313. DOI: 10.1021/ef060437d.

7. Vaughan, D. J., Pattrick, R. A. D., \& Wogelius, R. A. (2002). Minerals, metals and molecules: ore and environmental mineralogy in the new millennium. Mineral. Mag., 66(5), 653-676. DOI: 10.1180/0026461026650054.

8. Thompson, R., \& Oldfield, F. (1986). Environmental magnetism. London: Allen and Unwin.

9. Rzepa, G., Bajda, T., Gaweł, A., Debiec, K., \& Drewniak, L. (2016). Mineral transformations and textural evolution during roasting of bog iron ores. J. Therm. Anal. Calorim., 123(1), 615-630. DOI: 10.1007/ s10973-015-4925-1.
10. Dearing, J. A. (1994). Environmental magnetic susceptibility - using the Bartington MS2 System. Kenilworth, England: Chi Publishing.

11. Szumiata, T., Gawroński, M., Górka, B., Brzózka, K., Świetlik, R., Trojanowska, M., \& Strzelecka, M. (2013). Chemical, magnetic and Mössbauer effect analysis of road dust from expressway. Nukleonika, 58(1), 107-110.

12. Szumiata, T., Gzik-Szumiata, M., Brzózka, K., Górka, B., Gawroński, M., Świetlik, R., \& Trojanowska, M. (2015). Iron-containing phases in fly ashes from different combustion systems. Nukleonika, 60(1), 151-154. DOI: 10.1515/nuka-2015-0030.

13. Oh, S. J., Cook, D. C., \& Townsend, H. E. (1998). Characterization of iron oxides commonly formed as corrosion products on steel. Hyperfine Interact., $112,59-65$.

14. Brett, M. E., \& Graham, M. J. (1986). An electron back-scattering Mössbauer spectroscopy study of thin magnetite films. J. Magn. Magn. Mater., 60, 175-181. DOI: 10.1016/0304-8853(86)90098-3.

15. Dézsi, I., Fetzer, Cs., Gombkötő, Á., Szűcs, I., Gubicza, J., \& Ungár, T. (2008). Phase transition in nanomagnetite. J. Appl. Phys., 103, 104312-1-104312-5. DOI: $10.1063 / 1.2937252$.

16. Gorski, Ch. A., \& Scherer, M. M. (2010). Determination of nanoparticulate magnetite stoichiometry by Mössbauer spectroscopy, acidic dissolution, and powder X-ray diffraction: A critical review. Am. Miner. 95, 1017-1026. DOI: 10.2138/am.2010.3435 1017.

17. Da Costa, G. M., De Grave, E., Bowen, L. H., Vandenberghe, R. E., \& De Bakker, P. M. A. (1994). The center shift in Mössbauer spectra of maghemite and aluminum maghemites. Clay Clay Min., 42(5), 628-633.

18. Layek, S., Pandey, An., Pandey, Ash., \& Verma, H. C. (2010). Synthesis of $\gamma-\mathrm{Fe}_{2} \mathrm{O}_{3}$ nanoparticles with crystallographic and magnetic texture. Int. J. Eng. Sci. Technol., 2(8), 33-39. DOI: dx.doi.org/10.4314/ ijest.v2i8.63778.

19. Haley, G., Mullen, J. G., \& Honigt, J. M. (1989). First order change in hyperfine interaction at the Verwey transition in magnetite. Solid State Commun., 69(3), 285-287. DOI: 10.1016/0038-1098(89)90852-1.

20. Lee, S. W., Kim, S. J., \& Kim, Ch. S. (2006). Superexchange interactions in $\mathrm{MgFe}_{2} \mathrm{O}_{4}$. J. Korean Phys. Soc., 48(4), 583-588.

21. Omer, M. I. M., Elbadawi, A. A., \& Yassin, O. A. (2013). Synthesis and structural properties of $\mathrm{MgFe}_{2} \mathrm{O}_{4}$ ferrite nano-particles. JAIS-J. Appl. Ind. Sci., 1(4), 20-23.

22. Antao, S. M., Hassan, I., \& Parise, J. B. (2005). Cation ordering in magnesioferrite, $\mathrm{MgFe}_{2} \mathrm{O}_{4}$, to $982^{\circ} \mathrm{C}$ using in situ synchrotron X-ray powder diffraction. Am. Miner., 90(1), 219-228. DOI: 10.2138/am.2005.1559.

23. Leimalm, U., Lundgren, M., Ökvist, L. S., \& Björkman, B. (2010). Off-gas dust in an experimental blast furnace; Part 1: Characterization of flue dust, sludge and shaft fines. ISIJ Int., 50(11), 1560-1569. DOI: doi.org/10.2355/isijinternational.50.1560.

24. Hafner, S., \& Kalvius, M. (1966) The Mössbauer resonance of $\mathrm{Fe} 57$ in troilite $(\mathrm{FeS})$ and pyrrhotite $(\mathrm{Fe}$ 0.88S). Z. Krist.-Cryst. Mater., 123, 443-458.

25. Navarra, A., Graham, J. T., Somot, S., Ryan, D. H., \& Finch, J. A. (2010). Mössbauer quantification of pyrrhotite in relation to self-heating. Miner. Eng., 23, 652-658. DOI: 10.1016/j.mineng.2010.03.022.

26. Flanders, P. J. (1994). Collection, measurements and analysis of airborne magnetic particulates from pollution in the environment. J. Appl. Phys., 75, 5931-5936. 
27. Anshits, N. N., Vereshchagina, T. A., Bayukov, O. A., Salanov, A. N., \& Anshits, A. G. (2005). The nature of nanoparticles of crystalline phases in cenospheres and morphology of their shells. Glass Phys. Chem., 31(3), 306-315.

28. Taneja, S. P. (2004). Mössbauer studies of thermal power plant coal and fly ash. Hyperfine Interact., 153, 83-90.

29. Ram, L. C., Tripathi, P. S. M., \& Mishra, S. P. (1995). Mössbauer spectroscopic studies on the transformation of iron-bearing minerals during combustion of coals: Correlation with fouling and slagging. Fuel Process. Technol., 42, 47-60.

30. Bajukov, O. A., Anshits, N. N., Petrov, M. I., Balaev, A. D., \& Anshits, A. G. (2009). Composition of ferrospinel phase and magnetic properties of microspheres and cenospheres from fly ashes. Mater. Chem. Phys., 114, 495-503. DOI: 10.1016/j.matchemphys.2008.09.061.

31. Park, J. -Ch., Kim, D., Lee, Ch. -S., \& Kim, D. -K. (1999). A new synthetic route to wüstite. Bull. Korean Chem. Soc., 20(9) 1005-1008.

32. Jonczy, I., \& Stanek, J. (2013). Phase composition of metallurgical slag studied by Mössbauer spectroscopy. Nukleonika, 58(1), 127-131.

33. Vereš, J., Jakabský, Š., \& Šepelák, V. (2010). Chemical, physical, morphological and structural charac- terization of blast furnace sludge. Diffusion Fundamentals, 12, 88-91.

34. Wang, X., Zhu, M., Koopal, L. K., Li, W., Xu, W., Liu, F., Zhang, J., Liu, Q., Feng, X., \& Sparks, D. L. (2016). Effects of crystallite size on the structure and magnetism of ferrihydrite. Environ.-Sci. Nano, 3, 190-202. DOI: 10.1039/c5en00191a.

35. Kukkadapu, R. K., Zachara, J. M., Fredrickson, J. K., Smith, S. C., Dohnalkova, A. C., \& Russell, C. K. (2003). Transformation of 2-line ferrihydrite to 6-line ferrihydrite under oxic and anoxic conditions. Am. Miner., 88, 1903-1914. DOI: 0003-004X/03/1112$1903 \$ 05.00$.

36. Michel, F. M., Ehm, L., Antao, S. M., Lee, L. P., Chupas, P. J., Liu, G., Strongin, D. R., Schoonen, M. A. A., Phillips, B. L., \& Parise, J. B. (2007). The structure of ferrihydrite, a nanocrystalline material. Science, 316(5832), 1726-1729. DOI: 10.1126/science. 1142525 .

37. Stevens, J. G., Khasanov, A. M., Miller, J. W., Pollak, H., \& Li, Z. (2005). Mössbauer mineral handbook. Asheville, NC, USA: Mössbauer Effect Data Center, The University of North Carolina. Available from https://www.mtholyoke.edu/courses/mdyar/data/ MineralHandbook.pdf. 